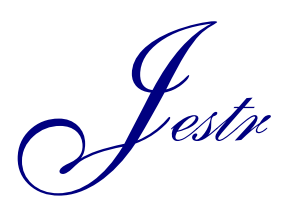

\title{
Working Principle Analysis and Control Algorithm for Analog Microgrid Control Sys- tem Based on Cortex-M4 Controller
}

\author{
Li Baoying ${ }^{1}$, Qu Chao ${ }^{1, *}$, Li Chen $^{2}$, Song Mingli ${ }^{2}$ and Yang Wanbing ${ }^{2}$ \\ ${ }^{1}$ School of Information Science and Engineering, Dalian Polytechnic University, Dalian 116034, China \\ ${ }^{2}$ School of Electrical Engineering and Telecommunications, UNSW Sydney, NSW 2052, Australia
}

Received 4 October 2018; Accepted 11 February 2019

\begin{abstract}
The modern power system is a centralized single-power supply system based on large power grids. However, with the popularity of new energy generation technologies, a distributed power generation technology based on new energy has the characteristics of high maintainability and flexible power generation mode. Thus, the mechanism of an analog microgrid control system based on Cortex-M4 controller with real-time measurement and tracking control function was proposed to solve the problems of unsatisfactory load in remote areas and the difficulty of power supply to satisfy the reliability, security, and diversity of power supply. The analog microgrid utilized the principle of three-phase analog microgrid interconnection composed of several grid-connected inverters. The three-phase analog micro-grid generated Alternating Current (AC) signal and other inverters worked in the grid-connected mode and adopted many loop control technologies, such as Proportional-Integral (PI) voltage tracking, PI current tracking, phase-locked loop, and digital feedback (2P2Z) compensation, to operate the grid-connected system in a stable condition. The accuracy of selecting a control algorithm was verified using experimental data. Results demonstrate that the three-phase symmetrical AC generated by an inverter can output $50 \mathrm{~Hz}$ sinusoidal current, $24 \pm 0.2 \mathrm{~V}$ line voltage in load, and $\leq 0.03 \%$ total harmonic distortion. The adjustment rate when changing the current root mean square of the load is small. The analog microgrid improves the system's instability caused by the complex operation of the microgrid system. The analog microgrid control system also enhances the requirements of hardware protection, such as overcurrent and overvoltage, and designs a software protection for islanding and circulation detections. This study provides references in the fields of system modeling, data processing, and control strategy, which can solve the contradiction between microgrid and power grid and satisfy the requirements of users for power supply.
\end{abstract}

Keywords: Microgrid; PID algorithm; Inverter circuit; Islanding detection; Phase-locked loop

\section{Introduction}

Distribution networks are an essential part of a power system. In a distribution network, a microgrid system is a new type of power distribution scheme that can integrate distributed power generation, energy storage, load, and protection. This distribution system can work independently or run in a grid. Therefore, it is a practical way of satisfying future developments.

Most of new energy generation forms, energy storage forms, and electronic loads are direct current (DC) or DC links. A DC power supply system will occupy a large proportion in future power supply, and developing gridconnected inverters will be promoted [1]. As a new energy generation technology, a grid-connected photovoltaic power generation system will influence the performances of public grids and their regulation ability. Thus, primary international energy and electrical institutions have formulated many technical specifications for this type of system; for example, the IEEE 1547 standards were compiled by the American Association of Electrical and Electronic Engineers in 1999,

\footnotetext{
*E-mail address: qushuai7696@163.com

ISSN: 1791-2377 @ 2019 Eastern Macedonia and Thrace Institute of Technology. All rights reserved. doi:10.25103/iestr.121.08
}

and the new grid-connected rules have been implemented in China since 2006. In 2010, the European Electrotechnical Standards Commission has promulgated EN50530 standards [1].

Scholars have conducted numerous studies on the steady operation, control, voltage output, and interference factors of analog microgrids. However, microgrid distributed systems are prone to power shortage in the action process, thereby reducing the efficiency of a grid-connected generation of microgrids. These systems demonstrate uncertainty and external interferences, which cause significant errors and delays to the control of the systems, thus affecting the stability and accuracy of the system operation [2-4].

On the basis of the preceding analysis, a design method for analog microgrid based on Cortex-M4 controller is proposed by studying the principle of three grid-connected inverters. When the grid is connected, the frequency is phase locked. A voltage regulator and a constant current loop are applied simultaneously. Moreover, three inverter technologies, a PI voltage, and the current tracking control system are designed to improve the load capacity of distributed gridconnected power generation, thereby improving the microgrid. The stability of the grid output voltage is tested. To enhance the microgrid's load capacity of the distributed grid-connected generation and the balance of the microgrid's output voltage, the system runs in the grid-connected genera- 
tion through frequency phase-lock, voltage stabilization and current stabilization loop, three inverters, PI voltage, and current tracking control.

\section{State of the art}

A microgrid is a small-scale power generation, distribution, and utilization system, which is composed of a distributed power supply, an energy storage system, an energy conversion device, monitoring and protection devices, and users' loads. However, for micropower sources, such as photovoltaics or wind power, the changes in external conditions may lead to changes in output power and cause problems, such as a drop in power quality. To solve the problems of instantaneous power outage, voltage surge, and sag caused by system faults, the power quality control device of a microgrid uses an energy storage device to provide fast power buffer, absorb or supplement electric energy, and provide an active power support. The device also performs active or reactive power compensation to stabilize and smooth the fluctuation in a grid voltage. CARR J A, BALDA J C, and MANTOOTH H A designed an energy storage system to improve power quality problems, such as voltage sags [6]. These scholars solved the effects of power quality problems and provided a reference for designing analog microgrids. However, stability was not mentioned in their research. When a microgrid works in a parallel operation with high-voltage grid networks, the microgrid is equivalent to an active power filter, which can compensate for harmonic currents and load spikes; when the micro-grid is disconnected from a large grid, the energy storage system can maintain voltage stability. In most renewable energy sources, such as solar, wind, and tidal energy, the output power will be changed at any time given the inherent nonuniformity and uncontrollability of energy. When changes are caused by external light, temperature, and wind, the output power of the microgrid power source will change correspondingly, thus confirming that the system requires an intermediate device to store energy [7] and effectively improving the stability of the microgrid; this feature has a certain reference value for selecting the design method. On the basis of the relationship between the microgrid and high-voltage grid networks, two modes of an isolated grid operation in the microgrid networks were selected by ZHAO Bo et al. and LIU Mengxuan et al.; first, the microgrid that is not connected to the large external grid is mainly used to solve the decentralized power demand in remote areas, such as islands and mountainous with few people, (e.g., Kythnos Island in Greece and Dongfushan Mountain in Zhejiang Province, China) [8-9]; second, considering that power grid failure or power quality cannot satisfy the requirements, YANG Xiangzhen et al. and SHI Shanshan et al. applied the principle of microgrid that was temporarily disconnected from the large external grid and entered the island operation mode [10-11], thus effectively improving the reliability and security of the load under their jurisdiction (e.g., the Bornholm microgrid in Denmark). In terms of stability, several experts have provided practical examples, which have certain practical project support and reference value for designing an analog microgrid. A different analysis of microgrid application in different countries has also been conducted. In accordance with the energy interaction between a microgrid and a large grid, ARULAMPALAM A et al. and WANG $\mathrm{He}$ et al. devised two modes of parallel operation in a microgrid; first, a microgrid can absorb power from but cannot output power to large grids (e.g., the Hachinohe microgrid in Japan); second, the microgrid and large network can exchange power in two directions freely; for example, the Demotec microgrid in German provided a solution, which can solve the problem of switching power, for the application among large grids. Currently, various microgrid experimental systems and demonstration projects in developed countries and regions, such as the United States and the European Union, embody worldwide research on different structures of a microgrid [14, 1516]. MIKEB, GIRIV, JUNJIK et al. proposed the design planning of a microgrid structural model to follow the principle of adapting to local conditions, and determine the microgrid capacity, power supply system, and wiring; furthermore, the model aimed to complete the overall network structure model design of a microgrid model based on comprehensively analyzing a load classification under the jurisdiction; this analysis was conducted in accordance with the requirements of safety, reliability, economy, flexible operation and nearby configuration, power supply radius and various local energy conditions (especially various renewable energy sources), and other relevant factors. In recent years, studying and applying the microgrid technology have developed rapidly in China, and several microgrid demonstration projects, such as the Dongfushan microgrid in Zhejiang Province and Dong'ao Island microgrid in Guangdong province, have been established. Table 1 summarizes the typical characteristics and key technologies of typical microgrid systems worldwide $[8,17]$.

Table 1. Typical Characteristics and Key Technologies of Microgrid Systems

\begin{tabular}{|c|c|c|}
\hline $\begin{array}{c}\text { Microgrid engineer- } \\
\text { ing }\end{array}$ & Typical characteristics & Key technology \\
\hline CERTS & $\begin{array}{l}\text { (1) Isolated and grid-connected operation modes; } \\
\text { (2) Kilowatt capacity and low voltage level; } \\
\text { (3) Three-phase AC microgrid structure and full discharge } \\
\text { control }\end{array}$ & $\begin{array}{l}\text { (1) Dropping control method; } \\
\text { (2) Safety control; } \\
\text { (3) Energy dispatching management }\end{array}$ \\
\hline Demotec & $\begin{array}{l}\text { (1) Isolated and grid-connected operation modes; } \\
\text { (2) Kilowatt capacity and low voltage level; } \\
\text { (3) Complex three-phase AC microgrid structure and radial } \\
\text { wiring }\end{array}$ & $\begin{array}{l}\text { (1) Energy dispatching management; } \\
\text { (2) Dropping control method }\end{array}$ \\
\hline Kythnos & $\begin{array}{l}\text { (1) Islanding network operation mode only; } \\
\text { (2) Kilowatt capacity and low voltage level; } \\
\text { (3) Three-phase microgrid or single-phase AC microgrid } \\
\text { structure and radiation wiring mode }\end{array}$ & $\begin{array}{l}\text { (1) Dropping control method; } \\
\text { (2) Master-slave control mode; } \\
\text { (3) Energy dispatching management }\end{array}$ \\
\hline Kyoto & $\begin{array}{l}\text { (1) Isolated and grid-connected operation modes; } \\
\text { (2) Kilowatt capacity and low voltage level; } \\
\text { (3) Three-phase AC microgrid structure and radial connection }\end{array}$ & $\begin{array}{l}\text { (1) Dropping control method; } \\
\text { (2) Master-slave control mode; } \\
\text { (3) Energy dispatching management }\end{array}$ \\
\hline
\end{tabular}




\begin{tabular}{|c|c|c|}
\hline & mode & \\
\hline Tung Fu Shan class & $\begin{array}{l}\text { (1) Islanding network operation mode only; } \\
\text { (2) Kilowatt capacity and low voltage level; } \\
\text { (3) AC/DC hybrid microgrid structure and radiation connec- } \\
\text { tion mode }\end{array}$ & $\begin{array}{l}\text { (1) Dropping control method; } \\
\text { (2) Master-slave control mode; } \\
\text { (3) Energy dispatching management }\end{array}$ \\
\hline Dong'ao Island class & $\begin{array}{l}\text { (1) Islanding network operation mode only; } \\
\text { (2) Megawatt capacity and low voltage level; } \\
\text { (3) AC structure of three-phase microgrid and ring connection } \\
\text { mode }\end{array}$ & $\begin{array}{l}\text { (1) Dropping control method; } \\
\text { (2) Master-slave control mode; } \\
\text { (3) Energy dispatching management; } \\
\text { (4) Hierarchical control strategy }\end{array}$ \\
\hline
\end{tabular}

On the basis of analyzing the above problems, a modelindependent PID controller is designed in this study to track the voltage and current of the analog microgrid in real time and realize the real-time monitoring of the stability of the analog microgrid operation, thereby effectively solving the problem of power shortage in the process of the microgrid distributed system and reducing the efficiency of the gridconnected generation of microgrid.

The remainder of this study is organized as follows. Section 3 describes the principle and technology of an analog microgrid that runs in a grid connection; builds the control model of the analog microgrid, implements different loop control algorithms, such as voltage and current tracking and even PID control algorithm; and realizes the design of software and hardware of the analog microgrid. Section 4 mainly measures the experimental data and analyzes the preliminary results. Section 5 summarizes this study and presents relevant conclusions.

\section{Methodology}

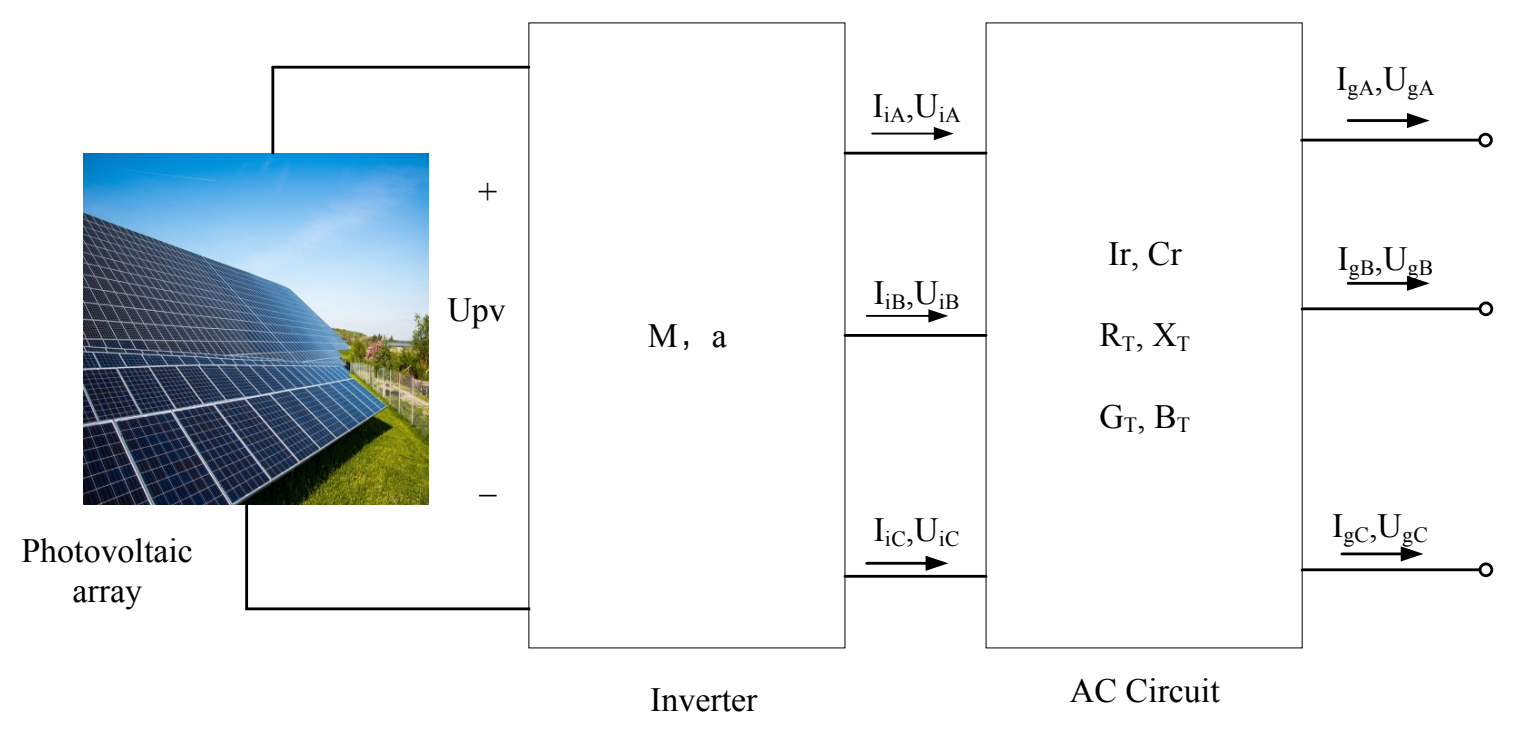

Fig. 1. Single-stage Photovoltaic Grid-connected System

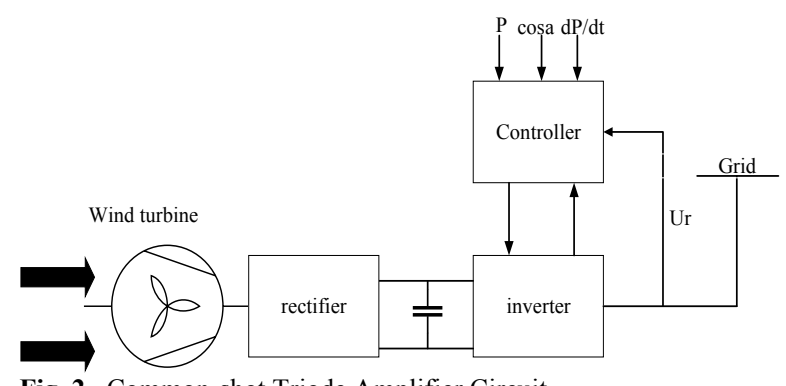

Fig. 2. Common-shot Triode Amplifier Circuit
3.1 Principle and Technology of the Analog Microgrid Interconnection

\subsubsection{Structure and Function of a Microgrid}

An analog microgrid is mainly used to simulate a microgrid loop. A $24 \mathrm{~V}$ regulated voltage is selected as the output line voltage of the inverters, and the generated inverters will not be too high. To complete the grid-connected function, a controller is required to adjust the $\mathrm{AC}$ output phase at any time. Interconnection controllers of low-power alternators and photovoltaic DC generators must use DC-AC inverters, which is the most extensively used method for adjusting the phase [18].

In a grid-connected system, the system is mainly based on grid-connected inverters, and the tracking control in the maximum power point of photovoltaic power generation is disregarded. Therefore, the selected AC power generation equipment mainly focuses on wind power generation and low-power diesel generator. A typical model of gridconnected direct-drive generators (power supply topology of wind power generation) is illustrated in Fig. 1, and a common-shot triode amplifier circuit of distributed wind power generation is depicted in Fig. 2 [1].

\subsubsection{Three-phase Inverter Technology}

Three-phase inverters are the most critical part of the power output stage of the grid-connected microgrid power generation system. Their primary function is to convert DC rectified by batteries or photovoltaic arrays or other alternators into $\mathrm{AC}$ power that can be synchronized with the grid network [19].

The system uses a three-phase bridge inversion topology; only one half-bridge circuit is more than a single-phase topology. However, three-phase inverters have fewer sinusoidal modulation schemes than single-phase bridge inverters. Three-phase inverters are mainly bipolar BP modulation and vector control. Bipolar modulation produces an SPWM 
pulse signal, whereas vector modulation produces SVPWM. Space vector pulse technology has the characteristics of a high utilization rate of DC voltage, but the control process is complex, thereby requiring a high operational performance of the control system. A bipolar modulation scheme is pro- posed to simplify the grid-connected control system. A circuit diagram of the three-phase smooth inversion is demonstrated in Fig. 3.

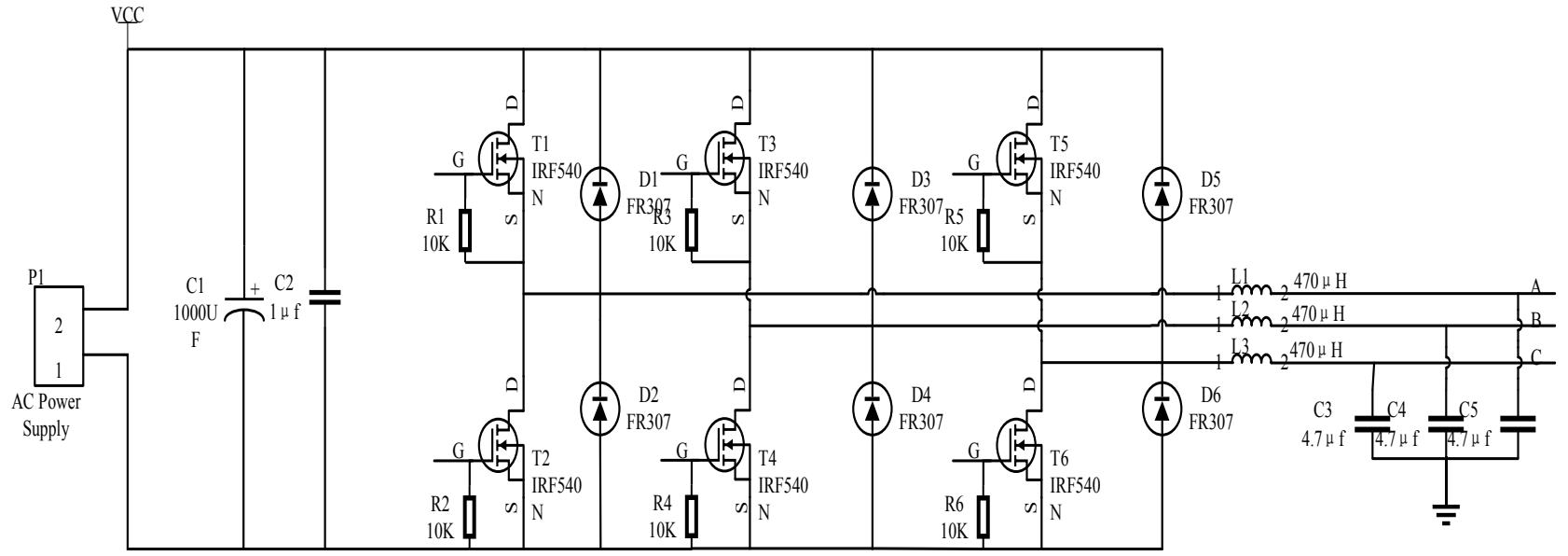

Fig. 3. Three-phase voltage bridge inverters

The voltage inverter (three-phase bridge-type inverter circuit) operates at a $180^{\circ}$ conduction mode; three sets of bridge arms are available, in which each group of conductive bridge arm angle is $180^{\circ}$; two other complementary conduction bridge arms exist simultaneously, in which each phase begins at a conducting edge of $120^{\circ}$ [20]. At any moment, the three bridge arms are operational. Each commutation is also conducted between the upper and lower arms of the same phase; this process is called longitudinal commutation. Only one capacitor is required in Fig. 3. Neutral point $\mathrm{N}$ is assumed between two capacitors in series to calculate the output voltage.

The system analyzes the working process of the threephase bridge. For Phase U, when Bridge arm 1 operates, $\mu_{u n}=U_{d} / 2$, and when Arm 4 works, $\mu_{u n}=-U_{d} / 2$. Thus, $\mu_{u n}$ is the waveform, and ${ }^{-U_{d} / 2}$ is the amplitude. Phases $\mathrm{V}$ and $\mathrm{W}$ are the same as Phase $U$, and the shape of the waveform is the same as $\mu_{u n}$; however, the phase turns by $120^{\circ}$. The current exchange process between Arms 1 and 4 is similar to that of the half-bridge circuit. When V1 is in the upper bridge, Arm 1 is converted from "on state" to "off state" because the current in load inductance cannot be changed abruptly. VD4 in lower bridge arm 4 leads on and continues the current. When the load current drops to 0 , and the current in upper bridge arm 4 is reversed, a commutation is completed. The load voltage equations for $\mu_{u v}, \mu_{v \mathrm{w}}$, and $\mu_{w u}$ are

$$
\left.\begin{array}{l}
\mu_{u v}=\mu_{u n}-\mu_{v n} \\
\mu_{v w}=\mu_{v n}-\mu_{w n} \\
\mu_{w u}=\mu_{w n}-\mu_{u n}
\end{array}\right\}
$$

The equation of load phase voltage $\mu_{u}, \mu_{v}$, and $\mu_{w}$ is demonstrated. In the equation, the $\mathrm{N}$ ' is load neutral point, and $\mu_{n n}$ is the voltage between the load neutral point and the input reference neutral point $\mathrm{N}$, as expressed as follows:

$$
\left.\begin{array}{l}
\mu_{u}=\mu_{u n}-\mu_{n n} \\
\mu_{v}=\mu_{v n}-\mu_{n n} \\
\mu_{w}=\mu_{w n}-\mu_{n n}
\end{array}\right\}
$$

Equation (2) can be rewritten as

$$
\mu_{n n}=\left(\mu_{u n}+\mu_{v n}+\mu_{w n}\right) / 3-\left(\mu_{u}+\mu_{v}+\mu_{w}\right) / 3
$$

A three-phase load is assumed to be symmetric; thus, we obtain $\mu_{u}+\mu_{v}+\mu_{w}=0$, and the equation for $\mathrm{N}$ point is

$\mu_{n n}=\left(\mu_{u n}+\mu_{v n}+\mu_{w n}\right) / 3$

\subsubsection{Grid-connected Key Technology}

The DC inverter is converted into an $\mathrm{AC}$ that is suitable for connection to the grid using a power-switching device. Through a flat wave action of RC filtering, a high-voltage SPWM waveform output by an inverter bridge is converted by the flat wave into a small sine current of total harmonic distortion (THD). After conforming the requirements of power grid interconnection with the electricity grid controller, grid voltage and the frequency and phase of the reference current with the given value of the difference are compared. The real grid current instantaneous feedback value of the difference is size. Then, error values are inputted into the PI regulator output amplitude. The section on account of the output power level is smoothed to filter out a high-frequency harmonic wave filter after the same frequency and phase AC is positioned parallel to the grid network, thereby completing the process of interconnection. Fig. 4. exhibits a block diagram of the grid-connected current control system.

The grid-connected technology must determine the control of the frequency and phase of an inverter before it is reconnected. The inverter parallel links between the important parts are the current- and frequency-tracking control. When the inverter is connected to the power grid network, the inverter voltage is uncontrolled by the inverter, which is clamped to the network by a grid voltage and into the output current of an inverter automatic mode. The current tracking control is used to prevent the inverter power shortage of the current flow backward phenomenon.

\subsubsection{Design of the Phase-Locked Loop}

The phase-locked loop technology plays a key role in a photovoltaic grid-connected system. A synchronous phaselocked loop generates the main reference current ${ }^{I}$ ref that is 
Li Baoying, Qu Chao, Li Chen, Song Mingli and Yang Wanbing/

Journal of Engineering Science and Technology Review 12 (1) (2019) 66 - 79

synchronized with grid voltage $U_{\text {net }}$, which is used as the setting of the current tracking loop to realize the control goal of the same frequency and phase of the grid-connected current and power grid voltage.

Phase-locked control links of a photovoltaic grid control system consist of two parts of hardware and software syntheses. The grid voltage signal through the zero crossing detection circuit in the whole form and its synchronization
TTL square wave signal are sent to a M451RG6AE capture port to capture its rising edge. The timer TIM to incremental counting mode is set to capture and trigger the signal interruption to reset the counting. The software phase-locked loop program flow of the grid-connected controller is displayed in Fig. 5.

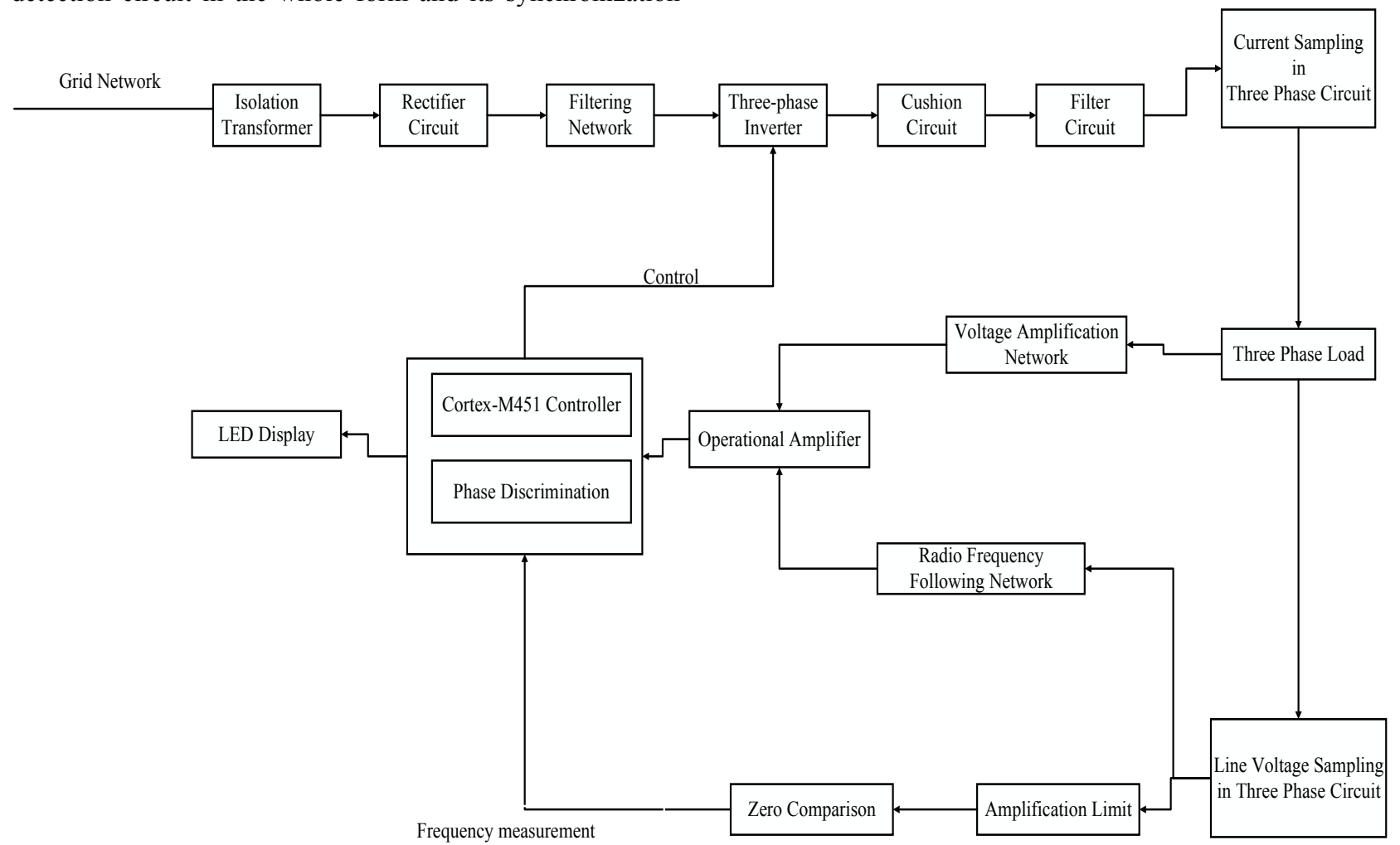

Fig. 4. Grid-connected Inverter Control Diagram

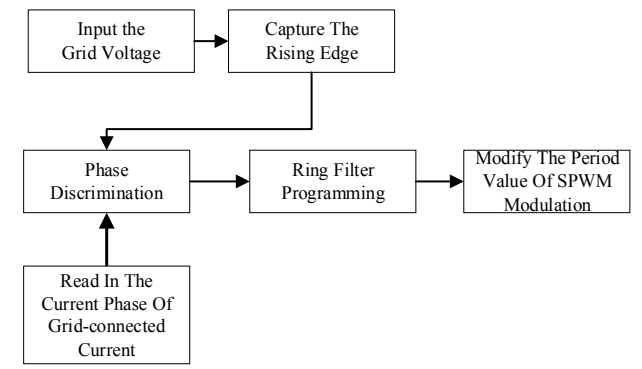

Fig. 5. Grid-connected Software of Phase-locked Loop

\subsection{Microgrid Control Design}

The microgrid controller has three working states, namely, grid-connected, current-sharing parallel, and islanding. The grid-connected state is the most complex working state in the entire microgrid control link. The islanding state is a basic output state of microgrid controllers. Inverters work in the constant-frequency and stable-voltage output states.

\subsubsection{Software Phase Detection and Voltage Following Method of Phase}

Phase locked and voltage following are fundamental issues in the grid-connected generation of a microgrid. In this study, Phase $\mathrm{U}$ is a quasi- $\mathrm{V}$ phase, and Phase $\mathrm{W}$ is $120^{\circ}$ backward at one time. The conversion frequency of an ADC device is $10 \mathrm{KHz}$, and the result is read using a DMA transmission channel. A hardware comparator has been included in the hardware circuit. Nevertheless, in actual measurement, mul- tiple approximations will occur near the zero point. Thus, the phase starting point is unable to determine accurately. No inversion phenomenon, that is, the software identifies 180 degrees at zero point, will be considered to ensure the accuracy of the current at the zero point [21]. The algorithm is based on $0^{\circ}$ after the phase of $30^{\circ}$. When the waveform voltage is positive, the zero identification is correct, and the phase information is transmitted to the SPWM phase controller, thus completing the phase-locked function of the Phase-locked loop (PLL). When the load current is 0 , the grid-connected inverters operate in the constant voltage state to prevent the voltage reversal. At this time, the output voltage of the inverter must be the same as the grid voltage, and the current loop still uses a PI regulator to limit the voltage of each circuit.

\subsubsection{Current-sharing Control}

When the load current works between 1 and $3 \mathrm{~A}$, the current distribution ratio of the two grid-connected inverters is 1:2 or 2:1. A dual-computer communication interface is added to the design to ensure that the inverters can work in 1-3 A. This interface is used to transmit the current distribution among the grid-connected computers under controllable conditions.

\subsubsection{Islanded Detection}

When the microgrid system runs in the grid-connected state, it can still encounter the problem of the sudden power outage. At this time, the microgrid will enter the island opera- 
tion state, but the grid and the microgrid lines maintain the electrical connection, which will cause the large grid to remain live during the grid maintenance, thus causing accidental damage to maintenance personnel. Simultaneously, if the power grid is interrupted, then the phase shift between the power grid and the microgrid will occur seriously. The detection process is presented in Fig. 6.

\subsubsection{Mode and Process of Microgrid Control Network- ing}

When no power supply exists or the quality is unfavorable, the system automatically cuts off the power supply access of the power grid and will supply power to the equipment on the microgrid through an inverted output alone. Isolated detection is the most basic state of generator operation in a microgrid; however, when connected to the network, antiislanding treatment is also required, that is, to prevent the operation in the islanded state when connected to the grid. The power flow of power generation energy flows from one side of the transformer to the $A C_{\text {out }}$ direction, where the inverters work independently for the microgrid.

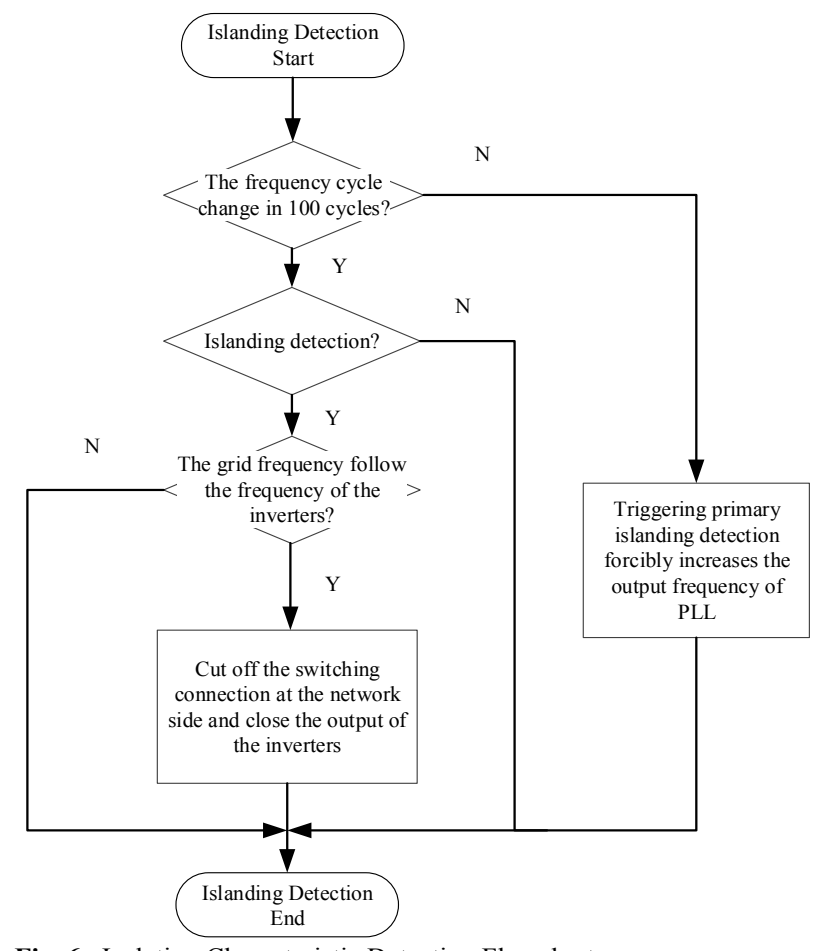

When the microgrid is connected to the grid, the controller requires voltage, phase, and frequency detections. Afterward, islanding detection is required to prevent the inverter from disconnecting in the grid-connected state. The output current trend of the microgrid to grid is under a gridconnected control; the direction is from one side of transformer $A C_{1}$ to $A C_{\text {out }}$. In the grid-connected state, the inverter can output power to the large power grid.

The current-sharing parallel state aims to combine several grid-connected inverters to supply power to the microgrid. The communication among the devices must be maintained, and the current must be managed.

The choice of control strategy can be based on the product design. Whether the system must switch from gridconnected state to islanding state, such as when the quality of power grid is too low or current backflow occurs, the controller actively cuts off the connection of large power grid and stops the output of inverters. The switching circuit of the networking controller is illustrated in Fig. 7.

\subsubsection{Root Mean Square (RMS) Calculation of Voltage and Current}

RMS is the effective value of voltage. The most accurate method for calculating $V_{r m s}$ is using RMS. The sinusoidal waveform is sampled through direct sampling method and DC coupling sampling with the ground voltage of $0 \mathrm{~V}$ as a reference point [22]. The RMS equation is

$$
R M S=\sqrt{\frac{\left(X_{i}-\bar{x}\right)^{2}}{n-1}}
$$

where $\mathrm{Xi}$ and $\mathrm{X}$ are the mean values of the voltage in a discrete sampling point and the voltage in a long period point, respectively.

\subsection{Implementation of Loop Control Algorithm}

\subsubsection{PID Algorithm}

An analog PID algorithm is demonstrated in Fig. 8. The left side is the target value of voltage following, and the right side outputs the inverter voltage.

Fig. 6. Isolation Characteristic Detection Flowchart

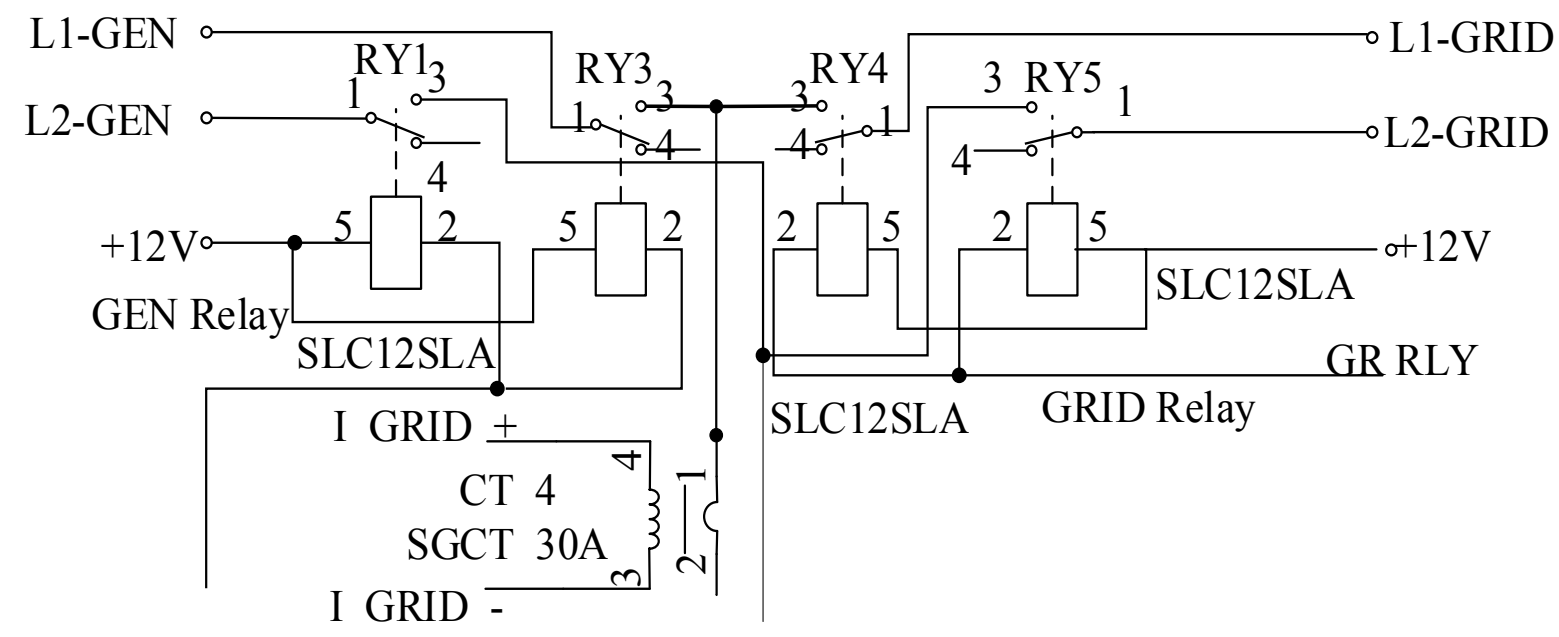

Fig. 7. Switching Circuit of a Grid-connected Control 


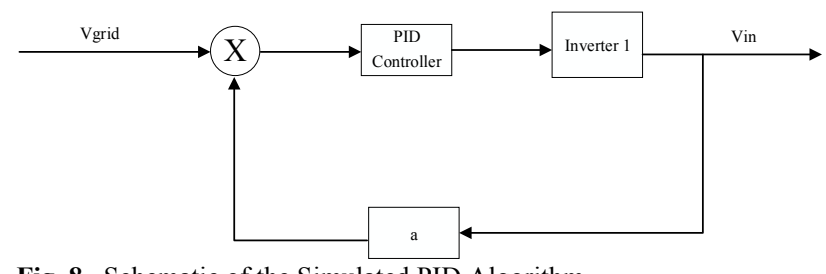

Fig. 8. Schematic of the Simulated PID Algorithm

\subsubsection{Realization of Loop Compensation Algorithms and Parameter Adjustment}

The loop design of the microgrid control system is mainly the loop compensation part. This design is aimed at improving the stability of power supply control. The system mainly uses incremental digital PID algorithm to compensate for the control model and acquire the ideal voltage following model. The ADC converter collects the difference signals among the RMSs of the voltages. These difference values are set to the PID controller, and the output of the controller can be the pulse signals on the SPWM pulse generator module.

Two PID algorithms are available; one is positional PID, as expressed in Equation (6), and the other is incremental PID, as defined in Equation (7). To adapt to the incremental PID derived from the control operation with improved adjustment performance, the incremental PID equation is written in the difference equation, as presented in Equation (7). The incremental PID algorithm is realized using a computational program [23]. The positional PID control algorithm is expressed as

$$
U(k)=K_{p} * e(k)+K_{i} * \sum_{j=0}^{k} e(j)+K_{d} *[e(k)-e(k-1)]+U_{o}
$$

where $U_{o}$ is the reference voltage of the control quantity, $U(k)$ is the output value of the Kth sampling, $K_{p}$ is the proportional coefficient, $K_{i}$ is the integral coefficient, and $K_{d}$ is the differential coefficient. The incremental PID algorithm is

$$
\begin{aligned}
& \Delta U(k)=U(k)-U(k-1) \\
& =K_{p} *[e(k)-e(k-1)]+K_{i} * e(k)+ \\
& K_{d} *[e(k)-2 * e(k-1)+e(k-2)]
\end{aligned}
$$

where $e(k), e(k-1)$, and $e(k-2)$ are the $\mathrm{Kth},(\mathrm{K}-1)$ th, and $(\mathrm{K}-2)$ th error values of sampling, correspondingly; $U(k)$ and $U(k-1)$ are the $\mathrm{kth}$ and $(\mathrm{k}-1)$ th sampling output values, respectively. ${ }_{p}$ is the proportional coefficient, ${ }_{i}$ is the integral coefficient, and $K_{d}$ is the differential coefficient.

\subsubsection{Phase-Locked Loop Control Algorithms}

Phase-locked loop controller must control the frequency and phase of SPWM wave generator. The output register of PWM is rewritten at different timing frequencies in accordance with the principle of the constant pulse output frequency of a single-chip microprocessor; that is, regardless of the frequencies that are refreshed with the same sinusoidal signal, only the writing frequency of the register is changed [24].
3.4 Hardware Design of the Analog Microgrid Control System

\subsubsection{Structure of the Microgrid Control System}

The hardware of three-phase grid-connected inverters is similar to that of DC-AC inverters. In accordance with the requirements of power supply, the hardware system is composed of Cortex-M4 controller, auxiliary power supply circuit, sampling circuit of inverting voltage and current, threephase bridge inverting circuit, three-phase filter circuit, transistor isolation driving circuit, tube current sampling circuit, and overcurrent and overvoltage protection circuits [25].

Cortex-M4 MCU system is the control core of each device in the system. The core control circuit includes crystal oscillator circuit, reset circuit, power supply circuit, and simulation debugging interface. A circuit diagram of the core board is depicted in Fig. 9.

\subsubsection{Design of the Controller and Detection System}

The voltage of the system is in the low voltage range. The sensor detection circuit is exhibited in Fig. 10. The currentlimiting electrons at the input of the voltage transformer are reduced to $22 \mathrm{~K}$, and the detection voltage range is reduced from $300 \mathrm{~V}$ to $30 \mathrm{~V}$.

The issue concerning the current sensor is that the phase will be offset slightly; this issue must be compensated for by an appropriate compensation circuit. Fig. 11 displays the design of the compensation circuit. Capacitance $\mathrm{C}$ and resistance $\mathrm{R}$ are used to compensate for a phase shift.

To reduce power consumption, the electronic conversion technology must make the power transistor work in the switching state, and the stable analog voltage can be obtained after the filter screens the switching frequency. However, the principle of area equivalence is used in PWM technology. Similarly, the sinusoidal signal is divided into several small parts that correspond to the pulse signal of the same proportion in accordance with the same time width, thus constituting the SPWM signal. An SPWM wave filters switching frequency through the LC filter and acquires the smooth sinusoidal signal; thus, the LC filter is the key to reducing the THD. In Fig. 12, the controller sends out three SPWM switching signals, in which the switching frequency is $25 \mathrm{KHz}$. However, the LC filter does not decrease significantly near the cutoff frequency. The cutoff frequency of the filter must be set at $10 \mathrm{KH}$. The system adopts a bipolar modulation mode (i.e., the upper and lower bridges are complementary to each other) given the particularity of threephase inverters. When the inverters work in the normal condition, the upper and lower tubes alternately output $50 \%$ square wave, and the output voltage of each phase is $V_{d} / 2$.

\subsubsection{Inverter Control Module}

A driving isolation circuit is a part of the power driver. Its main function is to amplify the power of the control signal and raise the level. Simultaneously, the circuit protects the control circuit from the accidental impact of high-current devices. The MOS driver circuit in the system must use $15 \mathrm{~V}$ to drive it completely. In Fig. 13, the driver circuit of IR2110 half-bridge MOS transistors is built. Therefore, three sets of MOS transistors are necessary to create the three sets of bridge arms, whereas three IR2110 chips are still required to drive the MOS bridge circuit. 
Li Baoying, Qu Chao, Li Chen, Song Mingli and Yang Wanbing/

Journal of Engineering Science and Technology Review 12 (1) (2019) 66 - 79

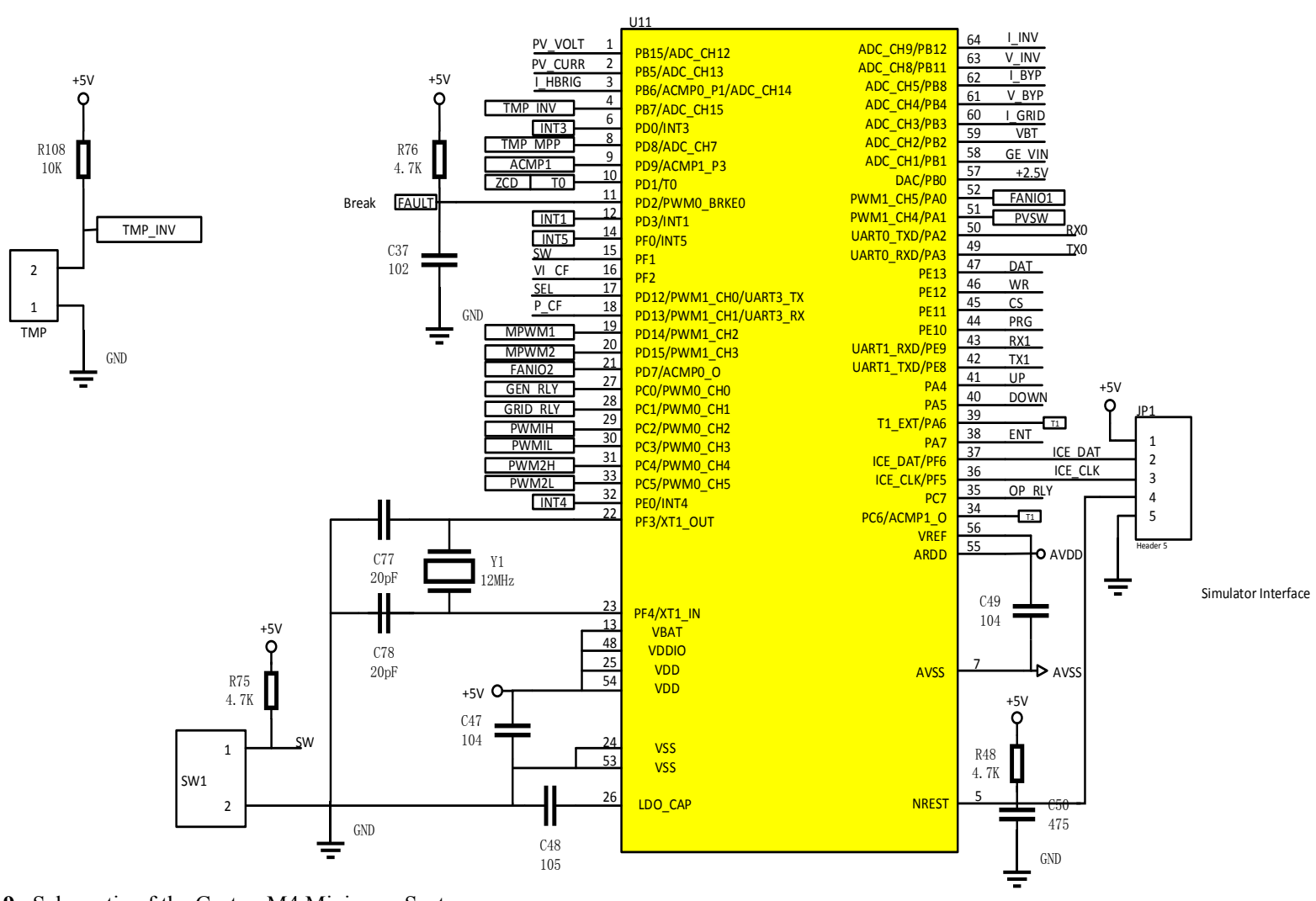

Fig. 9. Schematic of the Cortex-M4 Minimum System

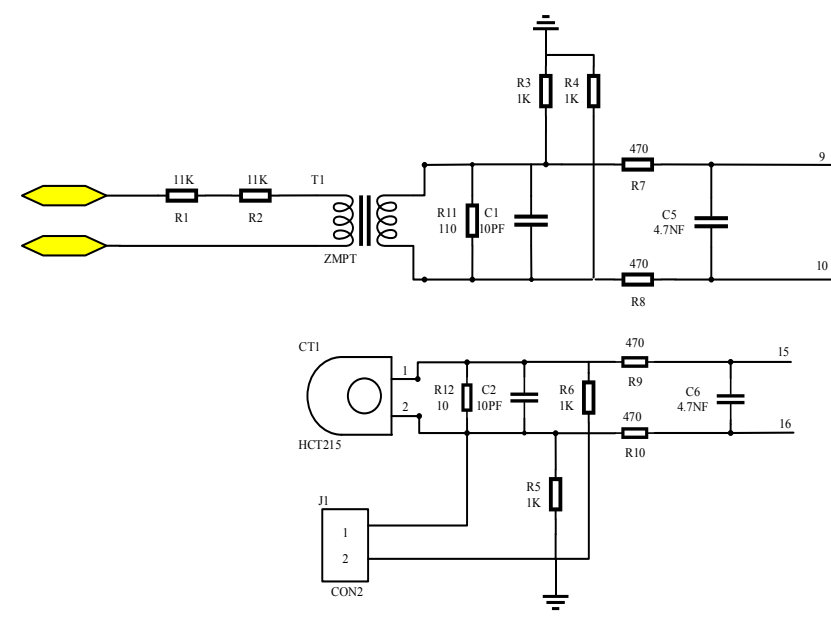

Fig. 10. Voltage and Current Sensor Detection Circuit

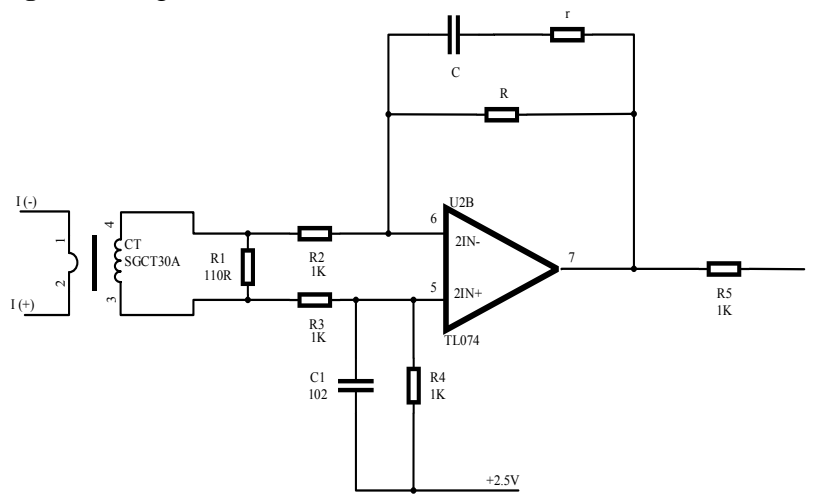

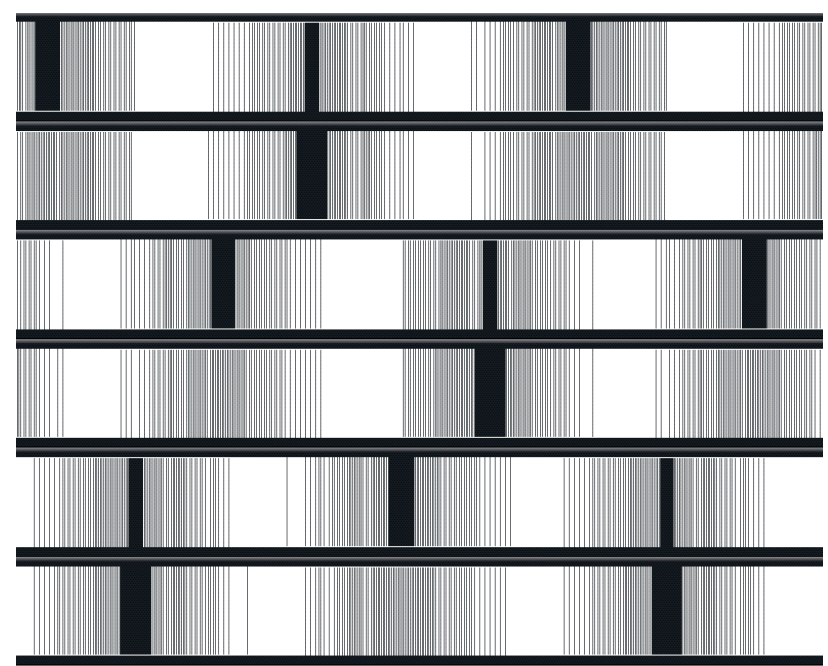

Fig. 12. Control Waveform using Three SPWMs

\subsubsection{Voltage and Current Sampling Module}

The electric energy measurement module and the voltage and current sampling circuit use completely different sampling methods. Voltage and current sensors use voltage and current transformers for sampling. In Fig. 14, the HLW8032 chip is a nonisolated connection between the chip and Phase U voltage. In Fig. 15, the principle of sampling indicates that the repetitive part directly uses the modular design method.

Fig. 11. Compensation Circuit for Current Sensor 


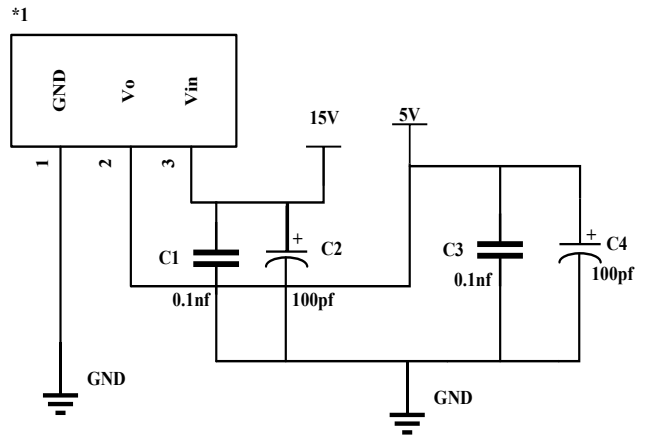

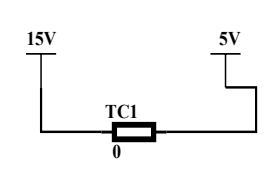

$15 \mathrm{~V}$ Output
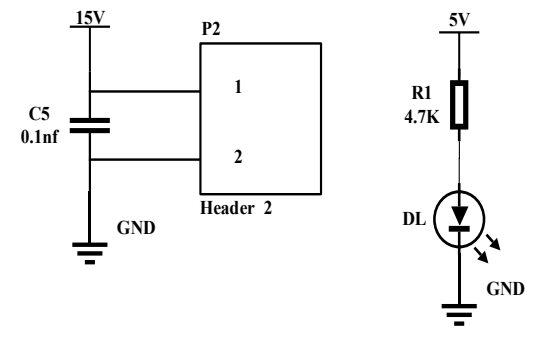
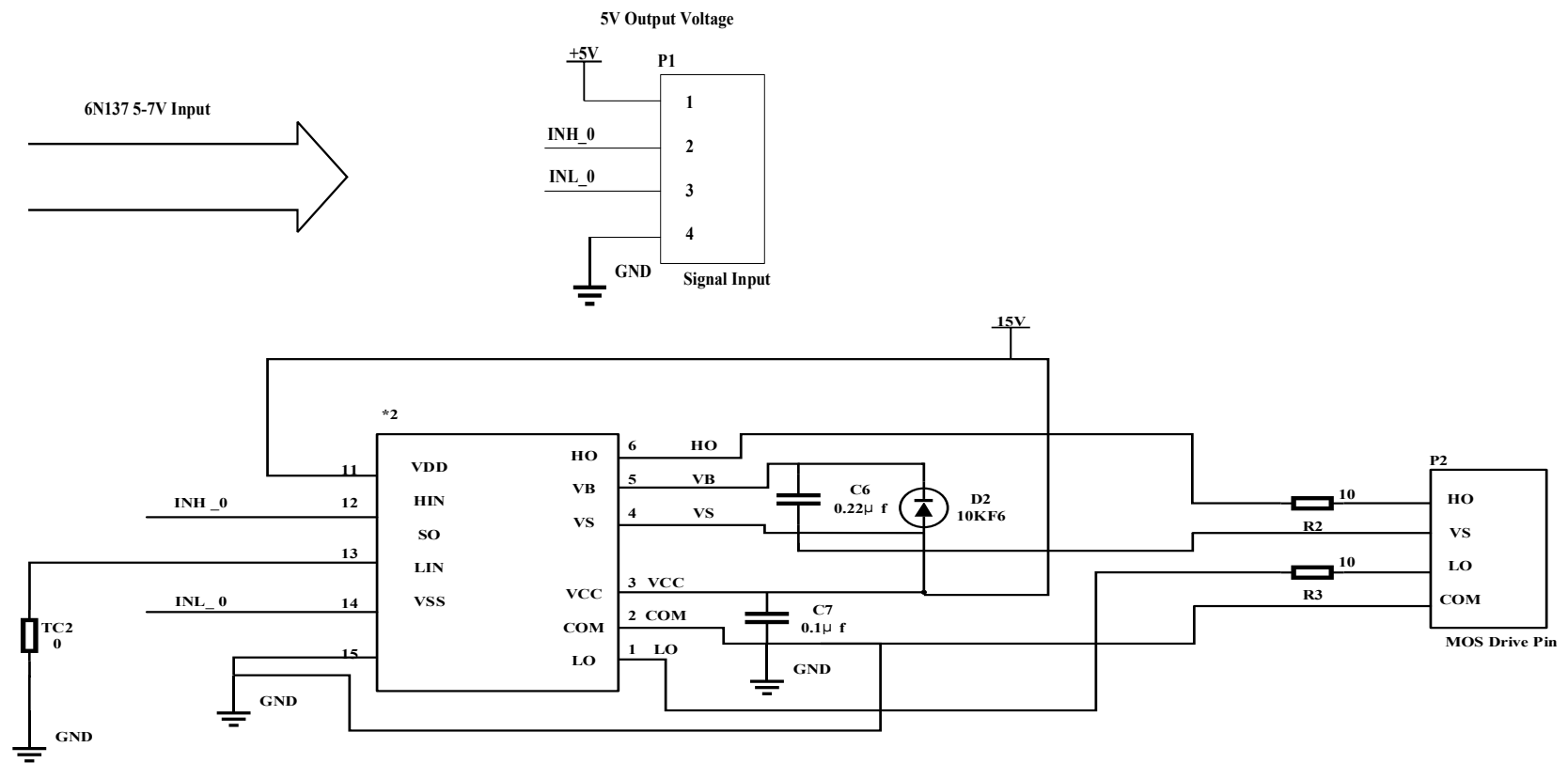

Fig. 13. Digram of an IR2110 Driver Board Circuit
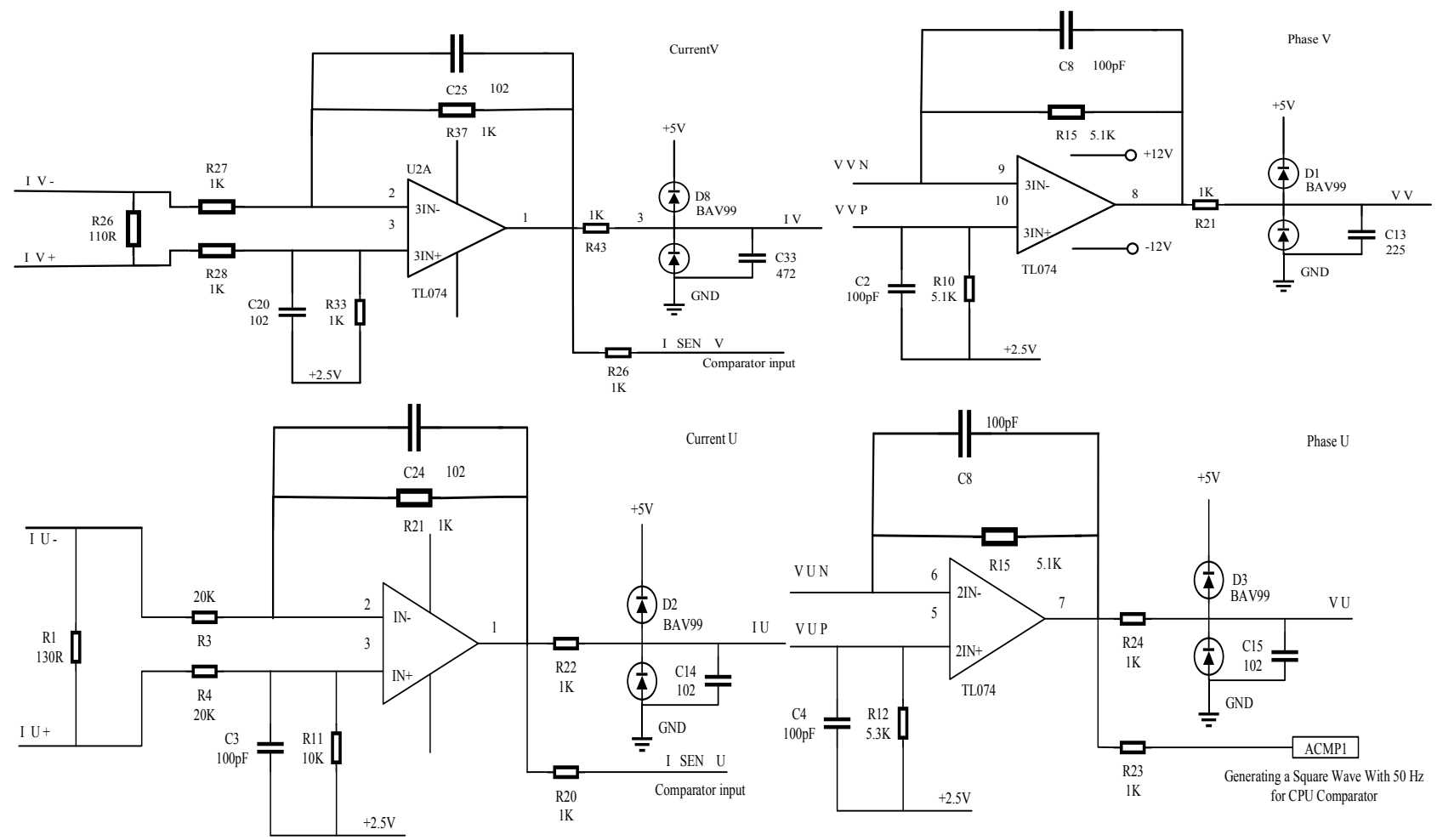
Li Baoying, Qu Chao, Li Chen, Song Mingli and Yang Wanbing/

Journal of Engineering Science and Technology Review 12 (1) (2019) 66 - 79

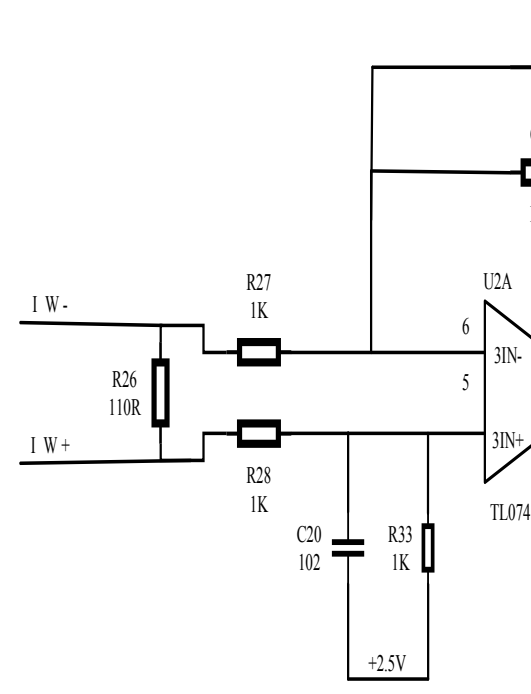

Current W
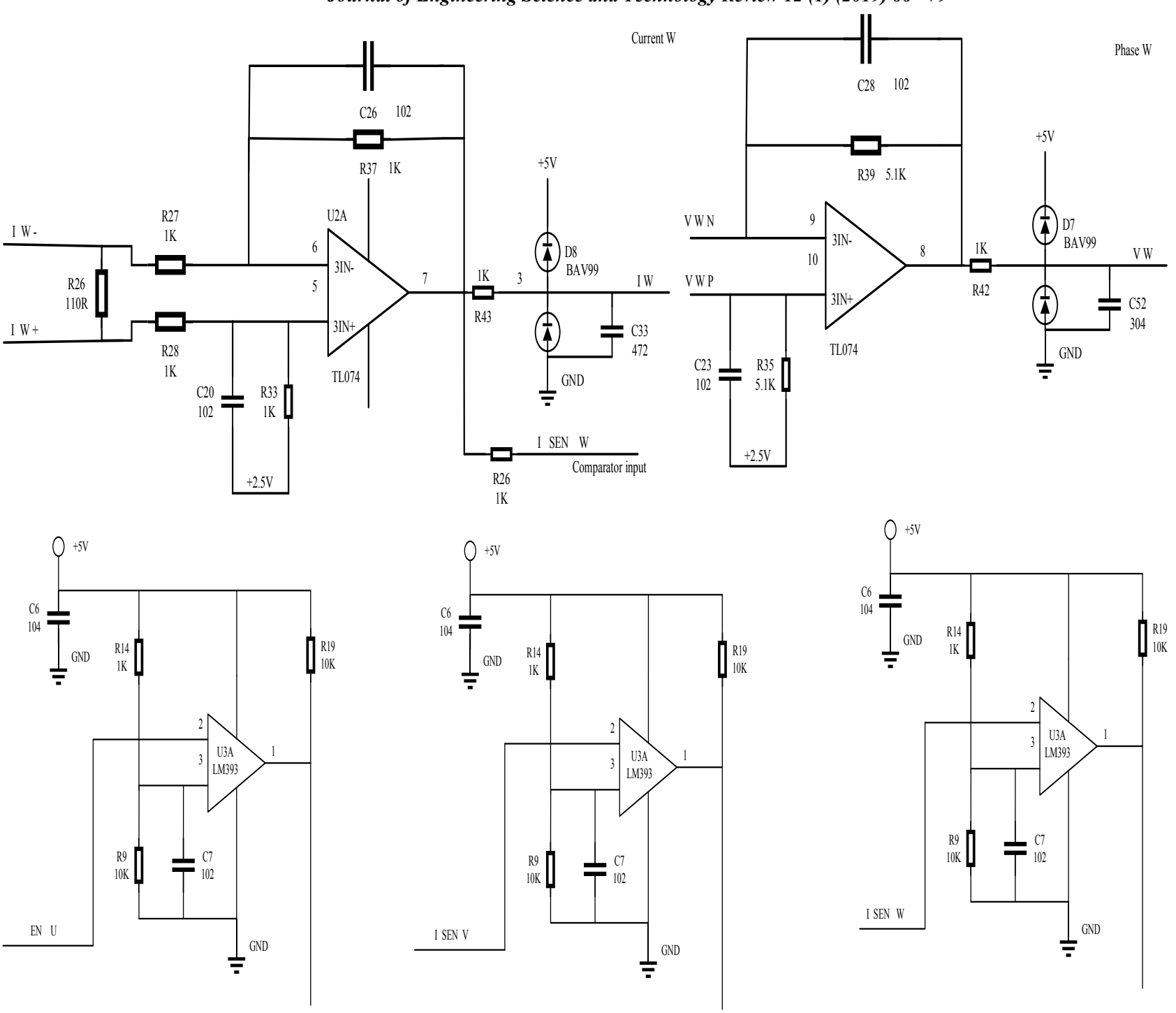

Fig. 14. Schematic of the Voltage and Current Sampling Circuit

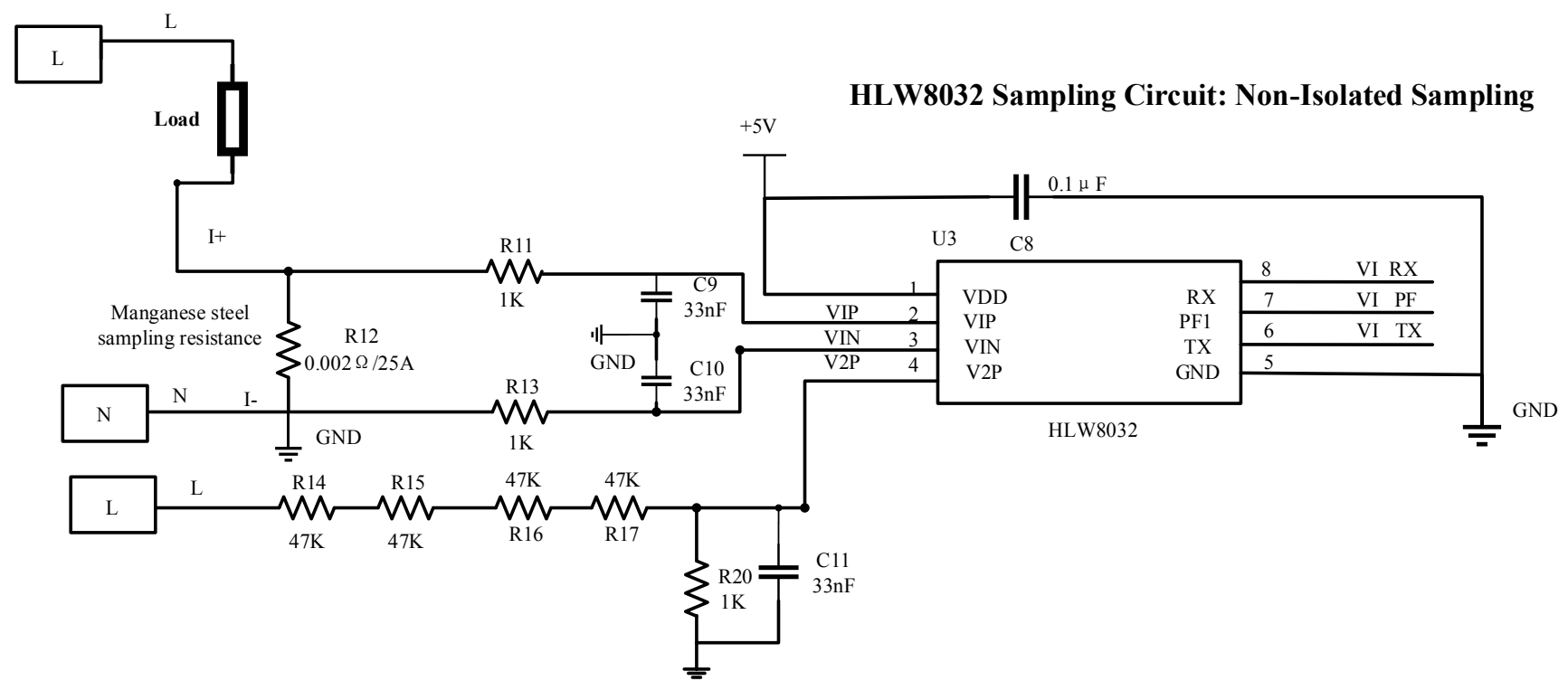

Fig. 15. Schematic of the HLW8032 Sampling Circuit

\subsubsection{Frequency Phase-locked Square Wave Generation} Circuit

To compare the accuracy of the phase-locked loop in software, a hardware-phase judgment circuit is added to compare the voltage signal from the sensor with the zero voltage

after the rise. A square wave signal that corresponds to the frequency is the output. The signal detector circuit is presented in Fig. 16, and the physical object is demonstrated in Fig. 17. 
Li Baoying, Qu Chao, Li Chen, Song Mingli and Yang Wanbing/
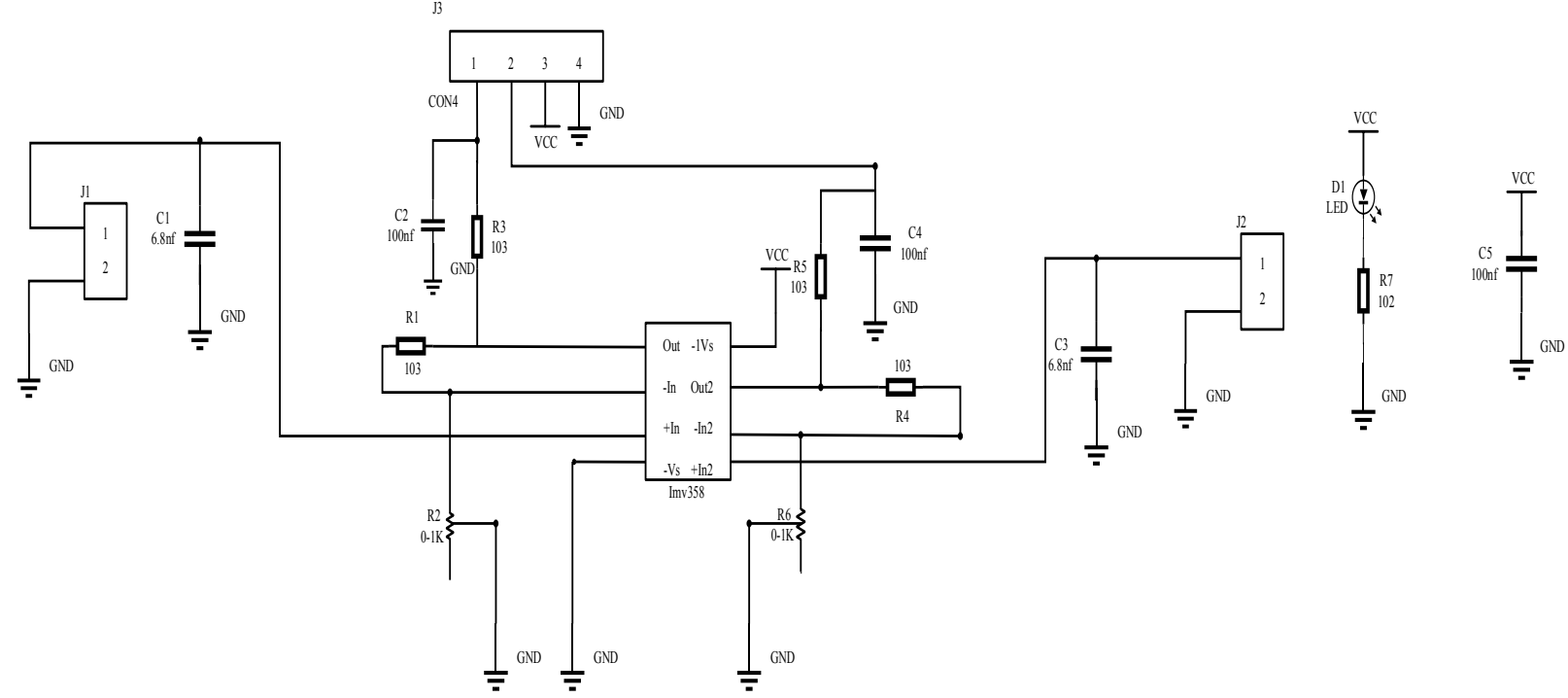

Fig. 16. Principle Diagram of the Signal Detector

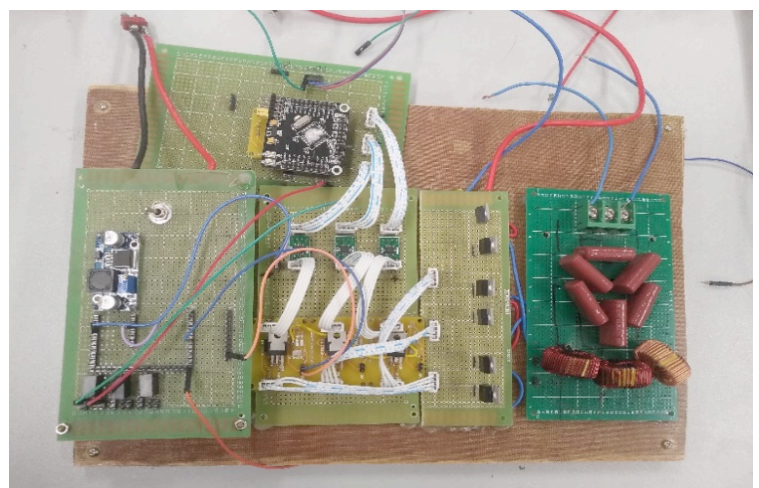

\subsection{Software Design of the Analog Microgrid System} 3.5.1 Overall Framework

The software system requires a complicated logic judgment and calculation to ensure the stable operation of the equipment. This section is mainly based on microgrid control as the overall system process. A diagram of the overall process is illustrated in Fig. 18.

Fig. 17. Physical Diagram of the System
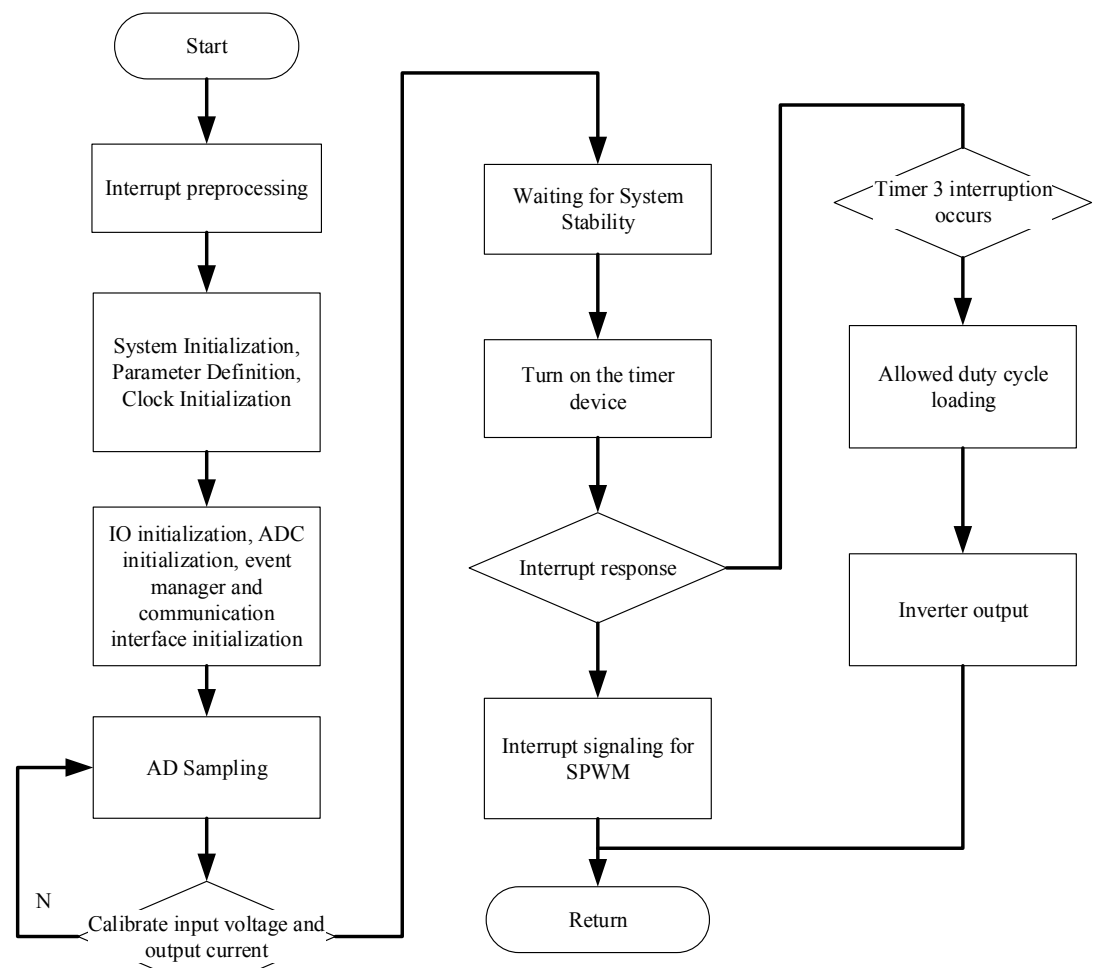

Fig. 18. Overall Diagram of the System 
Li Baoying, Qu Chao, Li Chen, Song Mingli and Yang Wanbing/

Journal of Engineering Science and Technology Review 12 (1) (2019) 66 - 79

\subsubsection{Voltage Following Control Loop}

Voltage and current sensors are connected to six AD pins of Cortex-M4 controller, and the values obtained from the controller are integrated into the deviation values after the filtering algorithm. The deviations are calculated using the PID algorithm, and the SPWM can be controlled by the pulse width. The PWM of the control output must have upper and lower limits (where the upper and lower limits are integrated into a single function when the PID algorithm is implemented); otherwise, a steering gear may work in a stalled state. The PWM will generate a large current and burn the steering gear in severe cases.

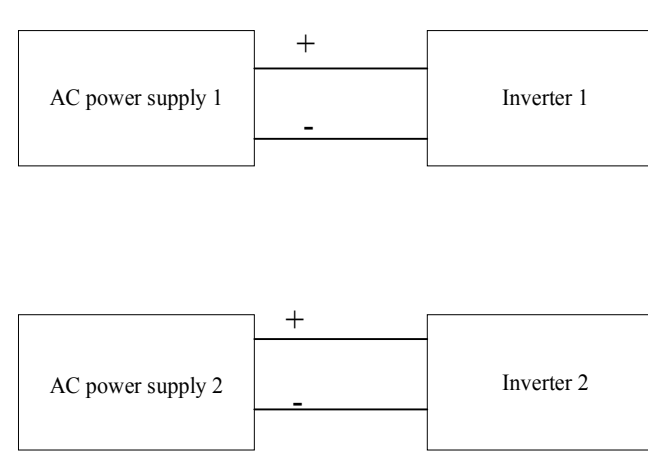

Fig. 19. Diagram of the Microgrid Simulation System

The results of the test show that the RMS of the current is $2 \mathrm{~A}$, the RMS of the line voltage is $24 \mathrm{~V}$, and the frequency is $50 \mathrm{~Hz}$. When the input voltage is $41 \mathrm{~V}$ and the load is 7 $\Omega$, the RMS of the line current in the load is $2.01 \mathrm{~A}$; moreover, the RMS of the line voltage is $24.1 \mathrm{~V}$, and the frequency measured by an oscilloscope is $50 \mathrm{HZ}$. For the THD of voltage, the output waveform is measured by power analyzer, and the THD rate is $2.3 \%$. The efficiency of inverter 1 can be measured with the input power of $52.7 \mathrm{~W}$, the RMSs of current and voltage on the load are measured with $I_{O}=2.01 \mathrm{~A}$ and $U_{o}=24.1 \mathrm{~V}$, and the efficiency is $92 \%$ in accordance with Equation (8).

$\eta=\frac{U_{O} I_{O}}{U^{*} I}$

The adjustment rate of Inverter 1 in the load is expressed as follows: when $I=0 \mathrm{~A}$, the output line voltage is $U_{o 1}$; when $I=2 A$, the output line voltage is $U_{o 2}$. The load ad-

\section{Result Analysis and Discussion}

\subsection{Single Operation of Inverters}

In Fig. 19, the switch $\mathrm{S}$ is closed, and only inverter 1 is supplied with a three-phase symmetrical AC power to the load. When the RMS of the load line current $I_{o}$ is $2 \mathrm{~A}$, the RMS of $U_{o}$ and the frequency $f$ of line voltage are obtained. The THD rate of AC bus voltage is less than $3 \%$. The efficiency $\eta$ of inverter 1 is larger than $87 \%$. When inverter 1 supplies power to the load, the result demonstrates that the RMS of the load line $I_{o}$ changes from $0 \mathrm{~A}$ to $2 \mathrm{~A}$, and the load adjustment rate is $S_{l 1} \leq 0.3 \%$.

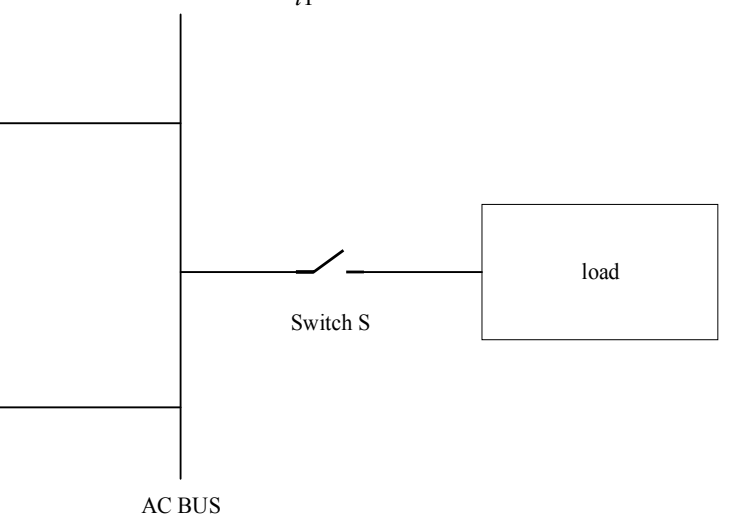

justment rate is $S_{l 1}=\left|\frac{U_{o 2}-U_{o 1}}{U_{o 1}}\right|=0.25 \%$. The relationship between current and voltage is displayed in Table 2, and the image fitted using MATLAB data is presented in Fig. 20.

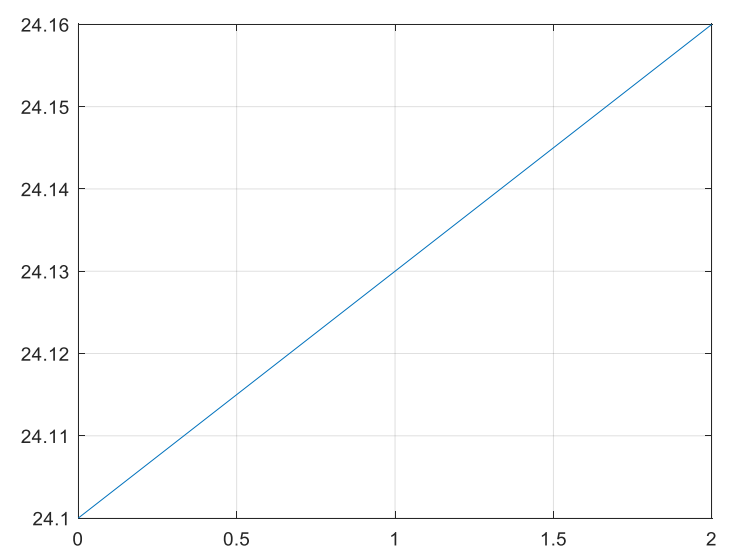

Fig. 20. Fitting Curve of Input Current and Output Voltage

Table 2. Relations between input current and output voltage

\begin{tabular}{c|c|c|c|c|c|c}
\hline I(A) & $\mathbf{0}$ & $\mathbf{0 . 1}$ & $\mathbf{0 . 2}$ & $\mathbf{0 . 3}$ & $\mathbf{0 . 4}$ & $\mathbf{0 . 5}$ \\
\hline Uo(V) & 24.100 & 24.102 & 24.106 & 24.108 & 24.111 & 24.115 \\
I(A) & 0.6 & 0.7 & 0.8 & 0.9 & 1.0 & 1.1 \\
Uo(V) & 24.118 & 24.121 & 24.124 & 24.127 & 24.130 & 24.133 \\
I(A) & 1.2 & 1.3 & 1.4 & 1.5 & 1.6 & 1.7 \\
Uo(V) & 24.135 & 24.138 & 24.142 & 24.144 & 24.149 & 24.151 \\
I(A) & 1.8 & 1.9 & 2.0 & 2.1 & 2.2 & 2.3 \\
Uo(V) & 24.154 & 24.157 & 24.160 & 24.163 & 24.166 & 24.170 \\
\hline
\end{tabular}




\subsection{Interaction Operation of Inverters}

Inverters 1 and 2 can output power collectively to the load; thus, the RMS of the load line current $I_{o}$ reaches $3 \mathrm{~A}$, and the frequency $f_{o}$ is $50 \mathrm{~Hz} \pm 0.2 \mathrm{~Hz}$. When the RMS of the load line current $I_{o}$ varies from 1 A to $3 \mathrm{~A}$, the output power of inverters 1 and 2 is kept at 1:1 distribution, and the absolute value of the difference between the output current of the two inverters is less than $0.1 \mathrm{~A}$. The load adjustment rate satisfies $S_{l 2} \leq 0.3 \%$. With the same condition, when the RMS of the load line current $I_{o}$ varies from 1 A to $3 \mathrm{~A}$, the output power of Inverters 1 and 2 can be automatically allocated within a specified range (ratio $\mathrm{K}$ alters $1: 2$ to $2: 1$ ). The absolute difference between the converted current of the output lines of the two inverters is less than $0.1 \mathrm{~A}$.

The experimental data show that, when the system runs at the parallel power supply, the RMS of the current is $3 \mathrm{~A}$, and the frequency is $50 \mathrm{~Hz}$. Parallel inverter 1 and normal inverter 2 adjust the load size. Accordingly, the RMS of the load line current is $3 \mathrm{~A}$, and the RMS of the line voltage is $24.1 \mathrm{~V}$. Furthermore, the frequency measured by the digital oscilloscope is $50 \mathrm{~Hz}$. The output power of inverters 1 and 2 is maintained at $1: 1$. The output power ratio is equal to the ratio of output current given two parallel power supplies. The two output currents of $I_{O}=1 \mathrm{~A}, 2 \mathrm{~A}, 3 \mathrm{~A}$ are measured, and the corresponding output voltage $U_{o}$ is recorded. The load adjustment rate is approximately $S_{l 2}=\left|\frac{U_{02}-U_{01}}{U_{o 1}}\right|=0.27 \%$, and the

line current difference between two inverters is less than $0.05 \mathrm{~A}$. The relationship between the three currents and voltage is summarized in Table 3 .

The output power ratio of Inverters 1 and 2 is adjustable. When the ratio of the output power of inverters 1 and 2 is set to $1: 2$ and 2:1, the data are obtained, as listed in Table 4.

Table 3. Relationship between three-phase current and voltage

\begin{tabular}{c|c|c|c}
\hline Io(A) & I1(A) & I2(A) & U0 (V) \\
\hline 0.98 & 0.49 & 0.50 & 24.01 \\
2.01 & 0.98 & 1.03 & 24.0 \\
2.98 & 1.49 & 1.48 & 24.98 \\
\hline
\end{tabular}

Table 4. Effect of input current and output voltage caused by different $\mathrm{K}$ ratios

\begin{tabular}{c|c|c|c|c|c}
\hline $\begin{array}{c}\mathbf{K} \\
\text { ratio }\end{array}$ & $\mathbf{I o}(\mathbf{A})$ & $\mathbf{I}_{\mathbf{1}}(\mathbf{A})$ & $\mathbf{I}_{\mathbf{2}}(\mathbf{A})$ & $\begin{array}{c}\text { Current } \\
\text { error }\end{array}$ & $\begin{array}{c}\text { Measured voltage } \\
(\mathbf{V})\end{array}$ \\
\hline $1: 2$ & 3.06 & 1.06 & 2.00 & 0.06 & 24.07 \\
$2: 1$ & 3.03 & 2.05 & 0.97 & 0.08 & 24.06 \\
\hline
\end{tabular}

\section{Conclusion}

To solve the problem of power supply and power resource allocations in the microgrid system, this study focused on the most critical problem that grid-connected inverters in the microgrid control system use DC as the input. A microgrid control system based on the Cortex-M4 controller was proposed to simulate the grid connection process. The loop compensation algorithms for the steady voltage and steady current and the grid-connected phase-locked loop algorithm were used to build and test the measurement model of electrical parameters. The algorithm for improving and operating the stability of the loop compensation in the microgrid networking process was analyzed. An experimental study was conducted. The following conclusions were drawn from this study:

1)The three symmetrical ACs generated by the system's inverters can output three $50 \mathrm{~Hz}$ sinusoidal currents.

2)The efficiency of the inverters in this system is high. The voltage of the load line is $24 \pm 0.2 \mathrm{~V}$, and $\mathrm{THD} \leq 0.03 \%$, thereby fully satisfying the requirements.

3)A change in the current RMS of the load makes the load adjustment rate small and satisfies the requirements of users.

4)The purpose of automatic power distribution is achieved by adjusting the proportional coefficient $\mathrm{K}$ value.

This study combined experimental data with professional theory and proposed the idea of the system's design and the implementation process of the analog microgrid system. The designed loop compensation algorithm and PID control algorithm are useful and practical, thus providing a reference for the study and the development of analog microgrids. The power for hardware platform is $60 \mathrm{~V}$, which will be life threatening for DC contacts that exceed $400 \mathrm{~V}$. Thus, no conclusion has been drawn from experiments that use high voltage. In the future study, the system will be combined with an inverter model in a $380 \mathrm{~V}$ AC network and will be revised to provide data support for applying a microgrid in high-voltage.

This is an Open Access article distributed under the terms of the Creative Commons Attribution License

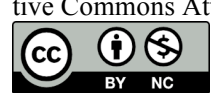

\section{References}

1. Chai, J. Y., Zhao, Y. Y., Sun, X. D., Geng, H., "Application and Prospect of Virtual Synchronous Generator Technology in Wind Power System". Journal of Power System Automation, 2018, 42(9), pp.17-25.

2. Liu, B., Huang, X. B., Cheng, W. F., Zhang, Z. X., Qiao, W. Z., "Design of a new type of high voltage series resonant power supply inverter". Journal of Xi'an University of Engineering, 2015 (29), pp. 105-109.

3. Xu, Q. S., "Distributed Generation and Microgrid Technology". Beijing: People's Posts and Telecommunications Publishing House, China, 2011, pp. 1-100.

4. Ed, P., "Living with Power System Harmonics". Journal of Plant Engineering, 1992, pp. 48-53.

5. Wang, C. S., Wang, S. X., "Study on some key problems related to distributed generation systems". Journal of Automation and Electric Power Systems, 2008, 32(20), pp. 1-4.
6. Carr, J. A., Balda, J. C., Mantooth, H. A., "A survey of systems to integrate distributed energy resources and energy storage on the utility grid". In: IEEE Energy 2030 Conference, Georgia, Atlanta: IEEE, 2008, pp. 1-7.

7. Lu Z. X., Wang, C. X., Ye, Y., et al., "Review of microgrid research". Journal of Power system automation, 2007, 31 (19), pp. 100-107.

8. Zhao, B., Zhang, X. S, Li, P., et al., "Optimal sizing, operating strategy and operational experience of a stand-alone microgrid on Dongfushan Island". Journal of Applied Energy, 2014(113), pp. 1656-1666.

9. Liu, M. X., Wang, C. S., Guo, L., et al., "An optimal design method of multi G objective based island microgrid". Journal of Automation and Electric Power Systems, 2012, 36(17), pp. 34-39.

10. Yang, X. Z., Su, J. H., Ding, M., et al., "Research on frequency control for microgrid in island ed operation". Journal of Power System Technology, 2010,34(1), pp. 164-168. 
Li Baoying, Qu Chao, Li Chen, Song Mingli and Yang Wanbing/

Journal of Engineering Science and Technology Review 12 (1) (2019) 66 - 79

11. Shi, S. S., Lu, Z. X., Min, Y., et al., "Analysis on frequency characteristics of islanded microgrid". Journal od Automation and Electric Power Systems, 2011,35(9), pp. 37-41.

12. Arulampalam, A., Barnes, M., Engler, A., et al, "Control of power electronic interfaces in distributed generation microgrids". International Journal of Electronics,2004,91, pp. 503-523

13. Wang H., Li, G. Q., Li, H. P., et al., "Transfer method of microgrid operation between grid connected and islanding modes". Journal of Electric Power, 2012,45(1):59-63

14. Mikeb, G., "Real-world microgrids-an overview". In: IEEE International Conference on System of Systems Engineering, San Antonio, USA:IEEE, 2007, pp. 1-8.

15. Yang, R. H., Huang, W., Gu, A. L., et al, "Structure and operation control of microgrids". Journal of Advances of Power System and Hydroelectric Engineering, 2010,26(1), pp. 48-55.

16. Tang, Z. P., Yang, H. P., Zou, Y. Q., et al, "Power Supply and Distribution Technology". Beijing: Electronic Industry Press, China, 2008, pp.1-16.

17. Wang, C. S., Li, P., "Development and challenges of distributed generation, the microgrid and smart distribution system". Journal of Automation and Electric Power Systems, 2010,34(2), pp.10-14.

18. Yang, W. J., "Simulation study on grid-connected photovoltaic power generation and micro-grid operation control". Nanchang: Southwest Jiaotong University Press, China, 2010,pp.1-25.
19. Yang, Y., Zhao, F. Q., Ruan, Y., Zhao, C. J., "Model current predictive control technology for three-phase grid-connected inverters". Journal of Electrical Technology, 2011, 26 (06), pp.153-159.

20. Wang, Z. A., Huang, J., "Power Electronics Technology". Beijing: Machinery Industry Press, China, 2002, pp. 1-12.

21. Chen, Y., Zhang, J. H., "Harmonic analysis and suppression strategy of SPWM inverters". Journal of Marine Electrical Technology, 2005 (1), pp. 28-31

22. Wang, C. S., Wu, Z., Li, P., "Research on key technologies of microgrid". Journal of Transactions of China Electrotechnical Society, 2014, 29(2), pp. 1-12

23. S, C., Wu, X. Y., Wang, Z. W., et al, "Practice and rethinking of microgrids". Journal of Power System Protection and Control, 2014, 42(5), pp.1-11.

24. Ding, M., Wang, W. S., Wang X. L., et al, "A review on the effect of large-scale PV generation on power systems". Journal of Proceedings of the CSEE, 2014, 34(1), pp. 1-14.

25. Hirase Y., Abe, K., Sugimoto, K., et al, "A grid connected inverter with virtual synchronous generator model of algebraic type". Journal of IEEE Transactions on Power and Energy, 2012, 132(4), pp.371-380. 